\title{
Un inventario de la catedral de Salamanca del siglo XIII
}

\author{
A. RIESCO \\ Universidad Complutense
}

El inventario, objeto de este estudio, se conserva en el Archivo catedral de Salamanca con la signatura: ACS, cajón 44, legajo 2, número 26. Dicho inventario, el más antiguo que se conoce de la catedral e institución capitular salmantina, fue transliterado, sin resolver las abreviaturas y respetando los signos peculiares de la letra manuscrita, por don Manuel Gómez Moreno y Martínez y publicado por él mismo en la "Revista de Archivos, Bibliotecas y Museos", el año 1902, bajo el título: "Inventario de la Catedral de Salamanca, año 1275" '.

Posteriormente (a.1962) fue catalogado por mi buen amigo y maestro, don Florencio Marcos Rodriguez, que lo recoge en su catálogo-inventario de la documentación capitular de Salamanca relativa a los siglos XII-XV ${ }^{2}$ comentándolo 0 , al menos, citándolo en otros trabajos suyos sobre la primitiva biblioteca del cabildo catedralicio de Salamanca.

Se trata de una copia simple de finales del siglo XIII, escrita sobre pergamino de $450 \times 370 \mathrm{~mm}$., a la línea tirada, con un total de 66 amplias líneas en letra gótica española de privilegios, es decir, en gótica caligráfica redondeada de tipo textual, en tinta color sepia un tanto desvaida y con algunas manchas, debido a la humedad.

Como elementos ornamentarles y decorativos del documento destacan las dos grandes iniciales: "EN" y «E" a plumilla (líneas 1 y 43) con fondos afiligranados a modo de siluetas, coloreadas en azul, rojo-grisáceo, verde y blanquecino, y numerosos calderones dispersos por el texto,

M. Gómez Moneno Martínez “Inventario de la Catedral de Salamanca (año 1275)", Revista de Archivos, Bibliotecas y Museos, 3. época, año VI, t. VII. 1902 (julio-septiembre) pp. 175-180.

2 F. Marcos Rodriguez, Catálogo de Documentos del Archivo Catedralicio de Salamanca (siglos x(1-xv). Salamanca 1962, 72, dc. n. 352. 
con valor de signos de párrafo, precediendo a los: «ltem» y, finalmente, varias letras mayúsculas de doble trazo: reforzadas o plenas, pero monocoloras.

El documento, no original, está datado en la "Era de mil et trezientos annos, en el mes de dezembrio, treze dias por andar", es decir, el 18 de diciembre del año 1275 de nuestra era y aunque omite el lugar de la escrituración, parece lógico sea Salamanca.

A mi entender, esta copia en romance castellano-leonés, por razón del tenor y de la lengua, se aparta mucho del latín y se halla ya no en un grado incipiente y de gran rudeza sino bastante desarrollado, de ahí que yo situe este documento a finales del siglo XIII o principios del XIV aunque no faltan quienes piensan que se trata de "copia coetánea" respecto del original. Posiblemente corresponda a 30 o 40 años más tarde de la fecha que aparece en el texto.

Este inventario es interesante no sólo por su contenido textual, por su antigüedad y por la lengua en que está escrito sino también por lo que representa desde el punto de vista cultural, artístico, documental y biblioteconómico. Junto con algunos testamentos del siglo $\mathrm{xII}$, en los que se contienen donaciones de libros, enseres y objetos de todo tipo, el inventario catedralicio de Salamanca de finales del siglo xIII, constituye el embrión y punto de partida de la célebre biblioteca capitular, base a su vez, de la futura biblioteca universitaria (siglos XIV-XVI), del propio archivo capitular y del tesoro y museo catedralicios.

Creo que vale la pena dar a conocer y poner al alcance de cuantos se interesan por la cultura, el arte, la lengua, el documentalismo y la biblioteconomía, una pieza documental de tan singular valor y tan representativa para la historia local.

A la transcripción del texto, he añadido un pequeño léxico de términos rarcs y expresiones en desuso que-espero-facilite la lectura y comprensión del mismo y, finalmente, un breve estudio y análisis paleográfico-diplomático de un típico documento:público, semipúblico o privado, de prueba, con marcado carácter descriptivo, pero indicativo de titulación y propiedad, tipificado con el nombre de «inventario" y referido, en este caso, a los bienes muebles de la principal institución y corporación eclesiástica salmantina: la catedral, sede y catedra del obispo e iglesia por antonomasia del cabildo y de la diócesis, con enumeración tanto de libros, ornamentos y vasos sagrados como de pinturas, cuadros, imágenes, enseres de ajuar y todo tipo de ropas, manteles, piezas y objetos, todos ellos ubicados en el recinto y dependencias catedralicias. 


\section{EL INVENTARIO, DOCUMENTO JURÍDICO-DIPLOMÁTICO}

Desde el punto de vista jurídico-diplomático el inventario no es otra cosa sino un instrumento descriptivo mediante el cual se enumeran, y de algún modo y con cierto orden, se describen, conforme a criterios no demasiados precisos, los bienes, objetos, joyas y papeles, libros, ropas, cosas, ajuares, etc. existentes o pertenecientes, bien a una persona particular, bien a una familia o instititución. El hecho de inventariar y, por consiguiente, el inventario, supone un acto de voluntad: obligada o de libre disposición y, la mayoria de las veces, obedece a una normativa prestablecida que reglamenta e impone, en determinadas circunstancias y tiempos, su elaboración, máxime en los momentos de toma de posesión de ciertos cargos, al rendir cuentas o con motivo del cese, traslado etc. de los responsables, administradores, tesoreros, párrocos... y, también, como consecuencia de un acto dispositivo de la autoridad que ordena la realización del mismo en cuanto a tiempo, lugar, modo y manera, bienes y objetos a inventariar y personas encargadas de la elaboración del inventario y de su escrituración, con el fin de que el inventario se convierta en documento testimonial y probativo.

La registración o asiento ordenado y control del patrimonio, bienes, objetos y cosas pertenecientes a la Iglesia de Roma o a las distintas iglesias, comunidades e instituciones locales que componen la Iglesia universal es un hecho tan antiguo como la cristiandad y la propia Iglesia.

Ya desde los primeros siglos del cristianismo, los concilios generales, provinciales y locales y aun los sínodos diocesanos, especialmente los concilios hispano-romanos y visigodos, se ocupan del patrimonio de la Iglesia y de los bienes eclesiásticos, velando por la sabia y recta administración de los mismos, por constituir éstos la base principal para el sustento de sus ministros, para la seguridad de las viudas, huérfanos y pobres ante el hambre y necesidades más perentorias, para garantía del apostolado y actividades a llevar a cabo por la jerarquía y las distintas iglesias e instituciones y el modo adecuado de garantizar la conservación de los edificios y fábricas de los templos, casas, cementerios, locales y centros de culto o de actividad religiosa, cultural, hospitalaria y social.

Cualquier fallo en la gestión administrativa y control de dicho patrimonio y bienes, entendiendo por tales no solo las propiedades rústicas y urbanas, es decir, los bienes inmuebles y semovientes, sino también todas las demás cosas y objetos pertenecientes a las distintas instituciones eclesiásticas, lugares píos, casas etc, de la Iglesia, ya se trate de objetos, vasos sagrados, ornamentos, cuadros, imágenes, libros, documentos, mo- 
biliario, ajuar, etc., en cuanto éstos también forman parte de dicho patrimonio. Sin embargo, el ejercicio y misión de vigilancia, administración, división y aplicación: suprema, intermedia o inmediata, de los bienes eclesiásticos que, por vía ordinaria y extraordinaria, corresponden al Romano Pontífice, a los obispos, superiores mayores y autoridades legítimas, si bien de hecho, por comisión delegada, ejercen estas funciones los arciprestes, deanes, arcedianos, párrocos y encargados de las parroquias, santuarios y centros de peregrinación y, sobre todo, los consejos económicos-administrativos de las diócesis y cuantos por mandato de la autoridad, conforme a la normativa canónica, tienen el oficio y cargo de administradores, tesoreros, habilitados, fabriqueros, ecónomos, párrocos, rectores y superiores de iglesias, santuarios y centros sociales, culturales o piobenéficos. La administración de los bienes eciesiásticos comprende: a) la conservación, mejoramiento y vigilancia de los mismos; b) la percepción, guarda, incremento $y$ empleo correctos de las rentas y frutos provenientes de dicho patrimonio y, c)la debida aplicación de bienes y rentas a los fines a que están destinados o deben destinarse, atendiéndose en todo a la normativa civil y canónica y velando con diligencia y empeño por el cumplimiento de la finalidad y necesidades que a dichos bienes les fueron asignados.

El concilio de Tarragona del a.516 en su canon 12, al hablar de los bienes de los obispos que mueren sin haber hecho testamento "ab intestato", prescribe que los clérigos de la diócesis o comunidad: presbiteros y diáconos, procedan con toda rapidez, una vez fallecido el prelado, a la elaboración fiel de un inventario en el que se detallen todas las cosas del difunto, a fin de que nadie se apropie de algo que corresponde a la iglesia local. Este canon se refiere tanto a los bienes muebles, inmuebles y semovientes como a las demás cosas del obispo fallecido, desde la más pequeñas e insignificantes a las mayores y más valiosas. De ahí que entienda y considere bienes inventariables, ciertamente las propiedades $e$ inmuebles, pero también las piezas artísticas y culturales, los objetos preciosos e, igualmente, los enseres domésticos y todo el ajuar episcopal. Asimismo establece que, una vez probada la ocultación o robo de cualquier cosa perteneciente a este patrimonio y caudal religioso, el autor o autores de estos actos fraudulentos deberán ser castigados y obligados a la devolución de lo sustraído $y$, si esto no fuera posible, a la restitución sustitutoria de su precio en proporción al valor estimatorio de lo robado, por tratarse de un hurto hecho al patrimonio y caudal religiosos ${ }^{3}$.

3 Concilios Visigóticos e Hispano-Romanos, Ed. de L. Vives -T. Marín- G. Martínez. Barcelona-Madrid 1953, 37-38. 
Algo parecido se observa en las disposiciones de los concilios I y || de Braga de los años 561 y 572, respectivamente, en sus canones 7 (Brac.l) 15 y 16 (Brac.II) relativos a la división de las rentas y a la administración y empleo de los bienes eclesiásticos ${ }^{4}$.

En ambos concilios se insiste en que "los bienes (muebles e inmuebles) y todo tipo de pertenencias de la Iglesia, aplicables en partes proporcionales al obispo, a los clérigos, al sostenimiento de los pobres y más necesitados y a la restauración e iluminación de las iglesias, deben conservarse para la Iglesia con toda diligencia y con buena conciencia y fidelidad a Dios, que ve y juzga todas la cosas.

Conforme a esta legislación, los obispos, por oficio, son los responsables principales de dicho patrimonio, señalando como colaboradores y corresponsables de esta misión y tarea santa a los presbíteros y diáconos. Sobre obispos, presbíteros y diáconos pesa el deber -dice el Concilio bracarense II- de saber al detalle cúales son la cosas propias de cada iglesia a fin de que se les dé a estas la aplicación y destino debidos, evitando asi que se disminuyan, oculten, malversen o roben; de no actuar con fidelidad y sumo interés en la administración y aplicación de dicho patrimonio se defraudaria a los pobres y dejarian de cumplirse los fines específicos asignados a tales bienes (cc. 15 y 16 del C.Brac.II).

Las cosas y bienes de las iglesias, según la legislación alfonsí (Partida I, tit. 14) no se pueden enajenar salvo en casos muy concretos y para necesidades graves y urgentes, por ser casas de oración y lugares donde Dios debe ser loado y servido, y los pobres, en tiempos de necesidad y de hambre, socorridos.

De los bienes eclesiásticos y de las herencias, fundaciones y donaciones para causas pias y, en general, del patrimonio eclesiástico, se ocuparon los Códigos Teodosiano y Justinianeo, las Partidas de Alfonso X, los fueros medievales, los concilios generales, naciones y locales y los sínodos diocesanos y, modernamente, la legislación civil y canónica, quedando, casi siempre, la función de inspección, control, administración y aplicación de dichos bienes en manos de la autoridad eclesiástica, en especial del papa y de los obispos y de sus colaboradores directos: los consejos administrativos y personas delegadas o que, por derecho eclesiástico, tienen la misión de representar en este punto a las distintas instituciones y asociaciones religiosas vinculadas a la Iglesia v.g.cabildos, casas y cen-

4 Concilios Visigólicos e Hispano-Romanos, o.c., pp. 72, 90, 91. 
tros religiosos, cofradías, hermandades, confraternidades, hospitales, seminarios, etc..

El Código de Derecho Canónico de la Iglesia latina, tanto en su versión del año 1917 como en la postconciliar y actual de 1983, resumen y reflejo de la legislación precedente, con relación a la vigilancia, cuidado, aplicación y administración de los bienes eclesiásticos, establece con precisión la obligación que pesa sobre quienes ejercen el oficio de administradores de dicho patrimonio, bien por derecho, cargo, u oficio, bien por delegación de la autoridad y designación institucional, a) de elaborar -en el tiempo forma y modo que se prescribe- «inventarios exactos y detallados" y b) de validarlos, suscribiéndolos ellos mismos con la presencia e intervención de testigos fieles, incluyendo en dichos instrumentos tanto los bienes muebles como los inmuebles y, en particular, todos los objetos preciosos y de valor pertenecientes al patrimonio cultural, pero sin omitir cualesquiera otros, facilitando en ellos la descripción y tasación (si es posible) de los mismos y comprobando la exactitud de dichos inventarios una vez concluidos (CDC de 1983,c.1283).

La Iglesia universal y las iglesias nacionales, territoriales, locales e institucionales, desde los primeros siglos hasta nuestros días, han mostrado gran interés por la conservación, acrecentamiento, buena administración y justo empleo de sus bienes y, en consecuencia, tanto la legislación general como la territorial, diocesana y particular, ha dejado bien claro cómo, cuándo y por quíenes han de hacerse y conservarse los inventarios de los bienes inmuebles, muebles y se movientes de la Iglesia e, igualmente, de otro tipo específico de bienes y objetos: litúrgicos, artísticos, culturales etc. entre los que figuran libros y documentos de archivo, vasos sagrados, ornamentos y demás piezas pictóricas, ornamentales o artísticas y cualesquiera otros utensilios, ropas, bienes y cosas ubicadas en iglesias, palacios episcopales, casas y centros parroquiales o en centros culturales, hospitalarios, sociales, etc, pertenecientes o vinculados a la Iglesia.

Teniendo en cuenta cuanto precede, desde la perspectiva jurídico diplomática, los inventarios -en cuanto documentos- pertenecen por su naturaleza y finalidad no a la categoría de documentos constitutivos sino mas bien a los típicamente descriptivos y probativos, ya que por una parte, en ellos se hace el recuento y enumeración, conforme a un orden y con cierta precisión, de todos o de parte de los bienes pertenecientes a una iglesia, a una casa, institución o persona, y por otra, se ofrece, aunque sea en forma somera y muy sucinta, la descripción de los mismos, con el fin de evitar que desaparezcan; Se intenta también responsabilizar al adminis- 
trador y, sobre todo, facilitar la identificación y adscripción de dichos bienes, objetos y piezas.

Por ser documentos indicativos de propiedad, sujetos a fines especificos y a vigilancia y administración por parte de titulares, administradores y representantes de la autoridad, los inventarios equivalen, de algún modo, a títulos de propiedad. De ahí que, en la mayoría de los casos, no pueda aplicárseles el calificativo de documentos indefinidos, incompletos o de tercer grado y, menos, el de meras noticias, si están revestidos de los elementos precisos y comunes a todo instrumento o escritura: pública, semipública o privada.

Los inventarios responden a una doble necesidad: 1) velar por la seguridad y conservación de dichos bienes y objetos e, igualmente, porque estos cumplan su finalidad: social, cultural, pia, litúrgica, asistencial, artístico-ornamental, social etc. y, a su vez, 2) garantizar dichos bienes mediante escritura validada por la autoridad o, al menos, por los encargados de elaborarlos y custodiarlos, observando las normas que para su redacción y validación se hallan establecidas, o siguiendo los usos y constumbres, si se trata de inventarios antiguos, medievales y renacentistas ${ }^{5}$.

\section{EL INVENTARIO CATEDRALICIO DE SALAMANCA DE 1275}

El inventario salmantino de 1275-cuyo texto corresponde a una copia simple de finales del siglo XIII o principios del XIV y no exactamente a la Era hispánica de 1313, es decir, al año 1275 después de Cristo, fecha que, sin duda, figuraría en el documento original-pertenece a la catedral de Salamanca y se circunscribe a dicha iglesia. En él se enumeran y describen, aunque sea en forma sucinta, no bienes inmuebles y semovientes sino libros, de contenido y carácter doctrinal, bíblico, teológico, litúrgico, homilético, patrístico, pastoral y literario pero, sobre todo, objetos de culto, ornamentos, vasos sagrados, ropas corales y litúrgicas, paños y manteles de altar, faldones, túnicas, mantos, palios de iglesia, numerosos objetos y piezas preciosas, jarras, utensilios propios de catedrales, pinturas, imáge-

5 CDC, a 1917, cánones 375-76, 470, 1296, § 2, 1299 \& 1, 2, 3, 1518-1521, 1522 \$2, 1523; CDC, a. 1983, cánones 1273-1277, 1283. Como complemento de esta legislación canónica sobre "inventarios", obligación de elaborarlos y modos diversos de inventariar, resultan interesantes, aunque sólo tengan alcance territoria! o local, las normas establecidas en los sínodos provinciales y diocesanos, sobre todo de los periodos medieval y renacentista. 
nes, coronas, rostrillos, velos, cuadros, crucifijos, y todo tipo de cosas, joyas y abundantes enseres de ajuar.

Respecto de la documentación y escrituras de archivo relacionadas directamente con la persona del obispo y con los privilegios de la catedral y de su cabildo, el inventario, en forma concisa y lacónica, dice: "En la otra (arqueta) fallaron las letras y los instrumentos et los privilegios de la Eglesia (catedral) et del obispo", advirtiendo que tales escritos formaban parte del llamado "tesoro episcopal».

La elaboración de dicho inventario correspondió a Juan Vermúdez, en otro tiempo tesorero de la iglesia catedral y probablemente ya fallecido, figurando como artífice principal fray Pedro Braollo y en calidad de ejecutores y responsables-en cuanto a cumplimiento de la voluntad del antiguo tesorero y a la entrega y justificación de lo contenido y enumerado-Juan Fernández, canónigo y Nuño Rodríguez, compañero, es decir, prebendado en expectativa a la espera de un beneficio vacante. Ambos debian hacer la entrega y comprobación ante el deán y cabildo o ante los delegados de estos, de todo lo inventariado.

Este documento enumerativo-descriptivo nos facilita, pues, los nombres de los autores: materiales y formales del inventario, instrumento jurídico-administrativo por antonomasia, y también los de los ejecutores responsables e intermediarios, encargados de demostrar a sus respectivos titulares y, en cierto modo, propietarios: el obispo y el cabildo catedralicio, la existencia de cada uno de los objetos, piezas, libros etc.

Un buen número de estas cosas y objetos se hallaban distribuidos por el interior del templo: altares, coro, sacristía, muros y demás dependencias de la catedral. El resto, especialmente, los libros y piezas de mayor valor artístico, pecunario y cultural, se encontraba en el interior de cinco arcas, tres grandes y dos más pequeñas, algunas con doble tapa y cerradura, procedentes, en cuanto a las arquetas, del tesoro del obispo. Por mandato del presidente y deán del cabildo y del conjunto de miembros capitulares, dada la importancia de lo contenido en estas arcas y arquetas, fueron abiertas ante los representantes nombrados para este efecto por la institución, don Diego y don Pedro Juanes, que se hicieron cargo de cuanto se contenía en ellas: libros, ornamentos, valiosas ropas y paños de la iglesia, objetos litúrgicos, vasos sagrados, utensilios diversos... y, sobre todo, un conjunto de documentos de gran importancia, las cartas, escrituras y privilegios relacionados directamente con la iglesia catedral y con el obispo, éste en calidad de cabeza y titular de la diócesis y de su iglesia matriz: la sede catedralicia y, también, con el cabildo, principal institución asesora y colaboradora de los distintos prelados de la diócesis de Salamanca. 
La entrega y recuento oficial de todo lo contenido en el inventario se hace en distintos actos o sesiones y en diferentes días, señalándose, dentro del mes de diciembre, el día 13 por andar, equivalente al 18 de diciembre y el 21 del mismo mes, festividad de Santo Tomé, es decir, Santo Tomás apóstol, unos días antes de la fiesta de Navidad, conforme al tenor documental: "el día de Sancto Thome-en la Era sobredicha-ante de la fiesta de Nathal, fezieron abrir las otras dos arquetas del thesoro del obispo et recibieron (su contenido) el dean et el cabildo de Salamanca".

Por tratarse de copia simple, el documento carece de validación notarial. Tampoco lleva las suscripciones correspondientes a los ejecutores y receptores del inventario y de lo contenido en él, ni de las autoridades representativas de la catedral: el obispo y el deán, autoridad-ésta últimaque actúa en nombre del cabildo y del propio prelado.

Antes de concluir este breve análisis sobre la estructura y contenido documental de esta pieza jurídica, me parece obligado advertir que la descripción de los libros enumerados es muy escueta y, en algunos casos, bastante imprecisa e incompleta v.gr.unos sermones, un libro, otro libro, un libro de san Isidro (Isidoro) en letra gallega etc. Es verdad que de algunos de estos libros se indica el autor y las primeras palabras del «incipit», pero la mayoría de estos inicios se encabezan con expresiones poco precisas e individualizantes, más "ad sensum" que literales, de ahí que no siempre coinciden con el título e "Incipit" reales de cada libro. Tampoco se puede asegurar qué concepto tienen de libro y si éste se corresponde con el de tratado o tomo, en uno o varios volúmenes.

Estas imprecisiones e inexactitudes explican el resultado incierto de la cantidad numérica de libros que figura en la última línea del documento (lin. 66), al concluir diciendo que la totalidad de los libros-se refiere, sin duda, a las arquetas-ascendía a 37:"Summa ystorum librorum precedentium:treynta et syete», a pesar de enumerarse sólo 35 títulos que, efectivamente, pueden equivaler a 37 tomos o volúmenes.

Este conjunto de obras, de carácter bíblico, teológico-patrístico, homilético, pastoral y literario, unido a los documentos episcopales y privilegios de la catedral, formaba parte del "tesoro del obispo" y estaba dentro de las dos arquetas más valiosas aunque su tamaño fuera más reducido. Sin embargo, en las primera líneas del inventario se enumeran los otros 15 títulos correspondientes a libros exclusivamente litúrgicos con un total de 27 volúmenes, algunos repetidos. Sus propios títulos: misales, evangelarios, salterios, manuales, oficieros ... indican que tales libros eran de uso corriente en los distintos actos litúrgicos v.gr.santa misa, oficio catedral y otros actos sagrados propios de la liturgia hispana. De ellos se servian 
los prestes y oficiantes de la catedral. Estos libros litúrgicos, por razón de su finalidad y uso frecuente: el culto diario, no estaban dentro de las tres arcas grandes, ni en los dos arquetas más pequeñas sino en el interior del templo, bien sobre los altares, atriles y facistoles, bien en el coro 0 , tal vez, en algún anaquel, alacena o estantería destinada a este fin, ubicada no sabemos donde, quizás en la sacristía o en alguna capilla 0 , acaso, dentro de un mueble ${ }^{6}$.

Resulta interesante comprobar cómo los autores del inventario resaltan las piezas, objetos, ornamentos etc. pertenecientes al "tesoro del obispo" como el núcleo más valioso de todo lo enumerado. Sin despreciar esa idea y realidad, yo me atrevo a sugerir -como indiqué en la introducción-otro aspecto no menos importante respecto de la parte procedente de dicho tesoro, siempre desde la perspectiva de la archivística, biblioteconomia y museología. Las piezas de archivo, biblioteca y museo, simplemente enumeradas, constituyen la base inicial de tres centros de carácter documental, científico-cultural y bibliográfico y artístico, que con el tiempo se convertirán en los tres más importantes depósitos del patrimonio artístico-cultural de la iglesia diocesana y catedral salmantina y de su incipiente Universidad: los archivos, catedral y diocesano, la biblioteca capitular y el museo diocesano-catedralicio, todos ubicados en distintas dependencias de la catedral, como siguen estándolo en la actualidad ${ }^{7}$.

\section{GLOSARIO DE TÉRMINOS Y EXPRESIONES DEL INVENTARIO HOY EN DESUSO}

Acerras de incienso $=$ recipientes cilíndrico o en forma de arqueta, bote, saquete... para guadar el incienso.

Acitarras = coberturas de tela o lienzo para recubrir e impedir la visión $y$, también, para dividir en compartimientos espacios amplios, como si se tratase de bastidores o biombos.

\footnotetext{
6 Aunque algunos títulos o nombres de estos libros litúrgicos, utilizados en la misa o durante el oficio catedral y en otros actos de culto, coinciden con los clásicos: Biblias, Salterios, Antif onarios... no aparecen los siguientes titulos: "Liber misticus", "Liber commicus o commatus", "Liber orationum", "Liber hymnorum et canticorum", "Passionarium", "Liber horarum...", ni tampoco el "Liber ordinum", o ritual de obispos para la administración de sacramentos y sacramentales, o el "Psalmographus" con los salmos, reducidos a uno o dos versículos, para cada antifona.

7 He preferido transcribir el típico signo tironiano: T, correspondiente a la particula copulativa, por "et" y no por "e", por considerarlo más adecuado, desde el punto de vista linguistico, a la época a que corresponde el texto y, también, porque cuando se explicita "in extenso", el escriba ha utilizado siempre "et" y no «e".
} 
Adobar( «estar de adobar o para adobar») = pieza u objeto etc. necesitado de reparación o sometido a restauración, transformación, arreglo, etc.

Aguamanil = recipiente de cristal, porcelana, metal o barro cocido, a modo de palangana, de distintos tamaños, con jarro de agua para la purificación de las manos y dedos de los celebrantes, que se utiliza en el «lavabo" de la misa y en otros actos litúrgicos.

Alcotonia, cotonia = tela blanca de algodón labrada normalmente con cordoncillo.

Aliofar-aljófar = objetos, ornamentos, insignias litúrgicas... exornados con pedrería, perlas pequeñas, etc.

Alquinnas = pañoletas sueltas de adorno, semejantes a velos bordados, para colocar sobre la cabeza y parte de los hombros de algunas imágenes, principalmente de las vírgenes y santas.

Amito-s $=$ prenda litúrgica de hilo, algodón, lienzo etc., de formato cuadrado, con cruz bordada en el centro, que los oficiantes: obispos, sacerdotes, diáconos y subdiáconos, al revestirse para celebrar, se colocaban sobre la espalda, bien ceñida al cuello.

Ampolla-s=vasija de cristal de cuello largo y angosto con cuerpo y base amplios y redondeados.

Apareiamientos $=$ conjunto de útiles de iglesia, principalmente manteles, paños de altar, sabanillas y ropa litúrgica.

Aquestas, aquestos $=$ estas, estos.

Ara (litúrgica) = pieza de piedra o de mármol, de formato cuadrado, bendecida o consagrada, que se coloca en el centro de altar, provista de orificios en el centro para albergar reliquias de santos; sobre élla descansa el cáliz y copones de consagrar, durante la misa.

Aramne = araña o lámpara de cristal con engarces de hilo 0 alambre metálico de plata, cobre etc. para sujetar, en los distintos brazos de que se compone, pinganillos y colgantes.

Arca-s cobiertas $=$ arcas 0 arcones grandes de doble tapa con dos o más cerraduras.

Arcas rasas = arcas de una sola tapa con una o más cerraduras.

Armella-s = argolla metálica para colocar en las paredes y puertas como sujetador o llamador $y$, también, pieza de anillo de formato variado que, a modo de espiga o pivote metálico, da fijeza y seguridad al candado en el que penetra. 
Arqueta-s de madera, marfil etc. $=$ recipientes de material noble con formato de caja, baúl, cofre, arca etc, bien de madera repujada, bien recubierta, parcial o totalmente, con láminas y adornos metálicos, bien con planchas de marfil o trozos de cuero. Su tamaño es más pequeño que el de las arcas, pero son mucho más artísticas y ricas, y se utilizaron para guardar libros, alhajas, joyas, vasos sagrados, objetos litúrgicos, dinero, documentos y piezas de especial significación y valor.

Bandas a rodas = paños a modo de echarpes o bandas amplias, semejantes a los humerales y, también, telas con carriles, calles o bandas redondeadas.

Barbero-Barvero = vasija cóncava semejante a la bacia antigua de barbero en la que se depositaba el agua para remojar la barba; A veces servía para recoger ofrendas: limosnas, dineros etc. o para otros fines. Puede equivaler, también, a bata o mandilón de lienzo, propio de criados y sirvientes.

Berneio-vermeio $=$ color bermejo, rojizo o cinabrio.

Biblia-viblia $=$ conjunto de libros sagrados.

Bochas-bochetas de fuste $=$ elementos ornamentarles y de adorno en forma de bolas de madera, de tamaño: grande, mediano o pequeño, unidos a un palo, astil o pie de sujeción.

Brago-braco-braço = brazo o palo: horizontal o vertical, de una cruz de marfil o de madera 0 , simplemente, astil-mango.

Branca-s; branco-s= blanca-s, blanco-s.

Breviario = libro con los textos del oficio divino, bien para el rezo de las festividades y de los santos, bien para los domingos y dias feriados, al que estaban obligados los sacerdotes y canónigos sometidos al "oficio catedralicio" diario. De ahí los nombres de los distintos breviarios: ordinario, dominical y santoral.

Cabildo-s (eclesiástico) $=$ corporación e institución de sacerdotes aprobada por la autoridad eclesiástica, adscrita a las iglesias catedrales, colegiales o parroquiales, para promover el culto divino oficial, auxiliar a los obispos en las solemnidades y actos litúrgicos de especial relieve y ayudar a los prelados en las tareas de gobierno, administración, asesoramiento y demás trabajos de la diócesis. Solian constar de "dignidades", "canónigos de oficio", "canónigos simples" y, con frecuencia, de "beneficiados" y de "personal auxiliar» civil.

Cadenado-s = objeto o libro sujeto con cadena o "encadenado".

Caderas = sillas con respaldo y, a veces, con brazos, a modo de poltronas, con algún parecido a la "silla curul» y al "sillón frailero». 
Calças = calzas, medias largas de distintos colores para recubrir las piernas y gran parte de los muslos.

Candelario $=$ candelero, candelabro .

Canónigo-s $=$ prebendado de un oficio o beneficio catedralicio o colegial, perteneciente y miembro del cabildo catedral y, en consecuencia, capitular.

Canudo-s = trozos de metal, martil, palo, etc., hueco y, a veces, ajustables entre si, para formar piezas completas.

Capa-s = vestidura litúrgica en forma de capa, hecha de paño de estemeña, lana, raso etc. que utilizan los obispos, canónigos, párrocos, sacerdotes, celebrantes etc. en procesiones y en otros actos litúrgicos, con la que se recubren los hombros y espaldas hasta por debajo de las rodillas. En la antigüedad, aparte de ser prenda de dignidad y distinción, sirvió para protegerse del agua y del frío. Tratándose de ropa o capa del hábito coral puede equivaler a manto de coro que recubre y se superpone a las demás piezas de que consta el traje oficial de los capitulares en los distintos oficios y ceremonias litúrgicas.

Capilla de fuste = Caseta: fija o portátil, de madera a modo de pequeño oratorio. En ocasiones equivale a nicho, hueco u hornacina de madera, por lo general, con imagen o estampa dentro.

Capistol, cafistol = atril, fijo o portátil, con pie amplio a modo de trípode que se recubre con paño exornado, sobre el que se colocan los libros litúrgicos (=facistol).

Capitular-res $=$ sacerdotes, miembros de los cabildos eclesiásticos, vinculados a los beneficios de las catedrales y colegiatas que hasta la Edad Media convivian con el obispo y estaban sometidos a regla y vida común canónica.

Capitulario-s = libro litúrgico de coro en el que se recogen las llamadas "capitula", es decir, los textos y lecturas bíblicas que se rezaban o recitaban durante las "horas del oficio divino", excepto en los "maitines", tras los salmos y las antífonas.

Casa, caseta, causeta = caseta, caja, estuche etc., bien de marfil, bien de madera o de metal, para guardar imágenes, objetos, reliquias, joyas, etc. En algún caso puede equivaler a capilla-relicario portátil.

Casula, casulla-s = vestidura litúrgica de lana, tisú u otro tejido de mayor o menor grosor, por lo general, con bordados y adornos que utilizan los sacerdotes para celebrar la misa y que se superpone y coloca sobre el alba o túnica interior, blanca y larga. 
Cendal, çendal = tela fina de seda o lino, normalmente, transparente.

Ceptro-s $=$ cetro o cetros.

Cesta para dineros = cesta de mimbre, tabla etc. para recoger las ofrendas de los fieles. Equivale a «limosnero» no metálico.

Christal $=$ cristal.

Cirial-es = candelabros fijos o móviles, con o sin varal, de metal o de madera y de distintas dimensiones, para colocar en ellos cirios gruesos o velas más delgadas. Se utilizan para la misa, en procesiones y en númerosos actos litúrgicos.

Cobertor $=$ cubre-altar o cubre-imagen, de paño o de tela gruesa, para evitar la manchas y el polvo.

Colletarios $=$ libros litúrgicos con las oraciones iniciales de las misas o «colectas» que se rezaban, antes de empezar la celebración, como plegaria común de la iglesia o comunidad, reunida para iniciar la procesión que precedía al santo sacrificio.

Conpannero-s, compañero-s = miembro del cabildo catedral con título de canónigo, beneficiado o racionero pero a prueba y sin estabilidad ni vinculación definitiva al cuerpo capitular y, en consecuencia, en expectativa de incorporación en un futuro próximo, siempre que se produjese una vacante.

Consiellas = conchas medianas o pequeñas para el agua y, también, recipientes o estuches en forma de concha para guardar joyas y otros objetos.

Corporales $=$ lienzos de formato cuadrado que se utilizan principalmente en la santa misa. Esta pieza de hilo, algodón etc. blanco, se extiende sobre el altar para colocar en ella los vasos sagrados: cálices, copones, custodias y las especies sacramentales de pan y vino que, mediante la consagración y transubstanciación, se convertirán en el cuerpo y la sangre de Cristo.

Cortibaldos-curtibaldos = cortinas pequeñas o medianas que tapan exclusivamente los huecos de las ventanas sin sobrepasar la repisa; se utilizaron también para recubrir y tapar el vasar y alacenas donde se colocaban platos, vasos y enseres de cocina.

Croça-croza = báculo episcopal rematado en cruz y, también, parte superior del báculo o cayado pastoral del obispo.

Coyro-cuero $=$ piel curtida con pelo que se utiliza como alfombra, o bien cuero depilado que se adorna con dibujos pintados o en realce a modo de guadamecí o guadamecil. 
Dalmática $=$ vestidura sagrada de buena calidad, por lo general, con adornos y ricos bordados, que utilizan los ministros (diáconos y subdiáconos) en determinadas celebraciones litúrgicas. Consta de abertura en el centro, para introducir la cabeza y de dos partes: delantera y trasera, que caen sobre el alba recubriendo el cuerpo del oficiante por delante y por detrás sin llegar a los pies y, finalmente, de dos amplias mangas, cerradas o abiertas.

Daquella-s - daquello-s = de aquella-s, de aquello-s.

Dar por nombre ( «dieron por nombre) = dieron o entregaron en nombre del sobredicho tesorero.

Deán = decano y presidente de un cabildo catedral, colegial o parroquial.

del-della,dello-desto = de el, de él, de ella, de ello, de esto.

delantrel $=$ delante de él o delante de el (sustantivo).

dellas-dellas, dellos-dellos = de ellas, de ellos; equivale tambien a: unas ... otras, una parte de ellas ..., otra parte.

Devandicha $=$ antedicha, antes dicha .

Diaspero, diaspro $=$ prenda 0 insignia preciosa (casulla, mitra) salpicada de puntas: lentejuelas, azabaches, piedras pequeñas, cristales etc. de diversos colores.

Doro $=$ de oro, d'oro, dorado.

Elas - Elos $=$ las, los,

Encenser $=$ incensario, braserillo movil con cadenillas y tapa agujereada que se utiliza para la incesacion de cruces, altares, imagenes, sepulturas y, tambien, del pueblo, quemando, en su interior, incienso, goma aromática etc. de suave olor.

Empronta, enpronta = impronta, cara o faz de un sello, de una matriz etc.

Entreteçido-a, emtretexido-a = entretejido, entretejida.

Epistolero = lector oficial o persona designada para leer, principalmente, la epístola de la misa. El término hace referencia al "subdiáconos.

Escaquel-escaque-s = es decir, tablero o paño con cuadraditos, rombos o casillas semejantes a las del ajedrez.

Esclavones de plata = eslabones o engarces de cadena de plata . 
Escudiella-s = escudillas, platos o fuentes, de tamaño pequeño a modo de tazas.

Escudos-s = representaciones, estandartes, etc. en forma de escudo con emblemas familiares (linajudos) o referentes a la institución, hermandad o corporación.

Escudo con corneias $=$ escudos heráldicos o genealógicos con distintas piezas y colores, rematados en puntas.

Escusar-Excusar = evitar, esconder, proteger el paño.

Espina = arista, espiga, trozo de madera con formato de columna, y también, pared divisoria con función de biombo o mampara divisoria y, tal vez, parte de una corona de espinas.

Estola = prenda litúrgica, de algodón, lana, tela etc. en forma de banda larga y estrecha con cruz en el centro y en sus dos extremos, que cuelga sobre los hombros del celebrante o ministro.

Evangelistero-s = sacerdote o diácono encargo por oficio de leer el evangelio en la misa. Puede equivaler, también, a evangelario, es decir, libro litúrgico con textos de los cuatro evangelios para la lectura en las misas, tanto dominicales como de los santos, días de fiesta y feriados. El inventario emplea "vangelistero» para libro y «evangelistero» para lector.

Façaleias-fazaleyas= toallas y paños de mano.

Fallez = falleba, cerradura, varilla metálica de cierre.

Fazaruello, fazaruelo = sudario o pañuelo grande de hilo, algodón ... para enjugarse el sudor y secarse la humedad o, tal vez, para limpiarse las manos y los dedos en el «lavabo". Quizás equivalga a "manutergio».

Ferrolos $=$ cerrojos.

Fierros $=$ hierros .

Follas = hojas de adorno para recubrir, guarnecer, exornar etc. imágenes, altares, cruces etc.

Frey-fray = hermano religioso o cofrade. Apócope de «fraile».

Frontal = paramento de tela bordada y, también, de tabla o de metal con dibujos, pinturas, bordados ... a modo de bastidor, con que se recubre $y$ adorna la parte delantera de la mesas de altar.

Frontal de peso $=$ frontal grueso, por lo general, forrado.

Fustán (de) = tela de algodón muy utilizada para forros de prendas litúrgicas, hábitos corales y, también, para recubrir imágenes, retablos y objetos. 
Fuste $($ de $)=$ de madera o palo.

Glosa - glosado = comentario de cierta extensión que acompaña al texto manuscrito o impreso. Suele ocupar los márgenes del propio texto que se lee, comenta o estudia; sólo en casos concretos va detrás.

Huevos de grifo $=$ molduras de adorno de figura oval con rizos y bucles, colocadas -o para colocar- bajo las volutas de las columnas y capiteles dóricos o de orden compuesto.

Lampada-s = lámpara-s.

Lámpara de aramne = lámpara de araña o lámpara de cristal con distintos brazos en los que se engarzan y cuelgan pequeñas piezas y pinganillos de cristal, roca etc.

Lanna = laña, grapa, abrazadera, varilla metálica ... para trabar, unir o sujetar.

Lave $=$ llave.

Lave de pecha = llave especial, rematada en venera, concha o cabeza de fino diseño, para llevarla colgada al pecho y que servia para fines diversos, especialmente para abrir los arcones donde se guardaban los "pechos" o tributos.

Labrada-s-labrado-s $=$ se refiere a paños, telas y tejidos bordados 0 , al menos, pintados y con adornos.

Leccionario-s = libro litúrgico que contiene las lecciones o lecturas del oficio divino de la catedral. En otros textos y lugares recibe el calificativo de "Commicus".

Limoges-Alimoges = ciudad francesa, célebre por las piezas finas de cristal, porcelana etc. salidas de sus fábricas v.gr.ciriales, lámparas, candelabros, aguamaniles, jarrones etc. En ocasiones tal expresión hace referencia no sólo al origen de fabricación sino también al formato y estilo "limosín».

Ligno = leño, trozo de madera de una cruz.

"Ligno domini» = "Lignum crucis», es decir, reliquia con un trozo auténtico de la cruz de Cristo o tocado a ella.

Luas-Luvas = guantes.

Majestad de Santa María = imágen de la Virgen, probablemente sentada y con corona.

Maniplo, manípulo = ornamento litúrgico semejante a la estola, pero mucho más corto, que se sujetaba en el antebrazo del obispo, sacerdote o diácono sobre el alba. 
Misal-es = libro litúrgico de altar con las oraciones y textos propios para la celebración de la misa tanto de los domingos y festivos como de los santos, festividades y misas votivas y de feria.

Mitra=insignia a modo de toca puntiaguda, de material rico, con adornos y bordados, con la que se cubren la cabeza los obispos y abades en determinadas celebraciones y actos litúrgicos.

Moscadero ("muscarium, mosquitero") = instrumento con formato de ventilador, abanico, pabellón o colgadura, revestido de plumas de ave: pavo, gallina etc. para espantar y cazar moscas.

Naveta de incensario = vasija o recipiente metálico con figura de quilla de navecilla (piragua) en la que se deposita el incienso que se ha de servir en la ceremonia de la incensación.

Oficiero-s = libro litúrgico con todo o parte del rezo diario del oficio divino y horas canónicas que debian recitar los sacerdotes y, especialmente, los canónigos y beneficiados de la catedral.

Onrramientos= ornamentos en sentido amplio, es decir, todo tipo de ropas litúrgicas: casullas, capas, albas, frontales, manteles y, tal vez, también objetos y utensilios destinados al culto divino, que se usaban en las celebraciones litúrgicas, procesiones, misas, oficios ...

Oral = especie de velo o paño fino de amplias dimensiones, utilizado por los papas, cardenales y obispos en celebraciones solemnes. Con él se recubrían la cabeza y, doblado, caía sobre el pecho y espaldas. En el contexto de este inventario, no parece pueda referirse al libro de oraciones o «liber orationum festivus» sino más bien a vestidura o traje episcopal y, en último término, a "sudario", sábana o lienzo para limpiarse el sudor.

Panno = paño , tela gruesa de algodón, hilo, estemeña... o con mezcla de dos o más hilaturas de uno o varios colores: "cárdeno", es decir, amoratado; "bermejo" de color bermellón o rojizo; "listado" = con listas rayadas o franjas de arriba a abajo; "pesado» = paño grueso.

Pendes de marfil = pendientes de marfil o colgantes de marfil, por lo general de adorno, colocados a modo de asas en arquetas y estuches.

\footnotetext{
Pennolas, penolas $=$ plumas, plumeros.

Pequenno-pequeno $=$ pequeño.
}

Pistoleros = epistolarios, es decir, libros litúrgicos con textos de las cartas de San Pablo y demás apóstoles y, también, del Apocalipsis y de los Hechos de los Apóstoles, para la lectura de las perícopas correspondien- 
tes a las "epistolas" de las distintas misas. Al encargado de leer dichas epistolas, en el inventario se le llama "epistolero".

Pora-poral-por al = para, para el.

Proseros-preseros-preçeros = libros litúrgicos de coro con las preces y responsorios que se rezaban en el oficio divino después de las lecciones de maitínes y tras los "capítula" de las horas canónicas menores. Puede equivaler al «liber precum» utilizado en determinados tiempos litúrgicos y en las ferias penitenciales.

Reponseros $=$ libros litúrgicos que contienen los reponsorios en verso de cada lección del oficio divino de domingos, fiestas y ferias.

Sagristia = sacristía .

Salterio-s = libro de coro denominado también “liber psalmographus" con los salmos y cánticos inspirados de alabanza, compuestos principalmente por David, de especial utilización en las catedrales para el rezo de las "Horas canónicas", pero sin las «lecciones (Leccionario) ni las "oraciones" (Liber orationum, Prosario, Oracional).

Senna-s = estandarte, enseña, bandera, guión.

Sermones= libros con homilias y escritos de los Santos Padres y, también, de los papas y autores sagrados. A veces equivale al "Liber Sermonum", es decir, conjunto de textos para leer en la misa después del evangelio en lugar de la homilía o predicación.

Sey $=$ sede, es decir, Santa Maria de la Sede o Catedral Vieja de Salamanca.

Sirgado-sirgada = relativo a un tipo de tela o paño denominado jerga o xerga y, también, al color rojo o sirgo.

Sirgo-sirga = jerga, xerga, tela gruesa, por lo general, tosca, para jergones, sayales, forros, etc y también para recubrir, proteger y envolver objetos. "Sirgo" probablemente es las contracción de "sirigo" y, más tarde, de "sirico" en relación con el color. jo".

So $=$ del «sub» latino, equivalente al «infra», es decir, «bajo», "deba-

Sobrel = sobre el, sobre él.

Someia $=$ se asemeja, se parece.

Stola-s $=$ estola-s.

Tabla con imagen = cuadro pintado sobre madera con figuras, escenas etc. 
Tapede $=$ tapete de mesa 0 de altar y, también, alfombra o alfombrilla para los pies.

Taula cobierta $=$ Tabla recubierta 0 forrada .

Teçida, texida $=$ tejida, tejido.

"Te igitur» = primeras palabras del "canon romano". Concluida la plegaria del prefacio y tras la recitación del "sanctus" de la misa, el celebrante, con los brazos extendidos hacia arriba, fijaba los ojos en le crucifijo para iniciar, con las palabras "Te igitur», la recitación del canon. El texto completo de esta plegaria solía colocarse en lugar bien visible sobre una tablilla, a modo de "sacra", situada directamente sobre el altar o colgada de alguna repisa en el retablo.

Textos cubiertos $=$ textos, oraciones, plegarias ... encuadrados en marcos de metal o de madera, como las «sacras de altar", por lo general, guarnecidos o recubiertos de láminas de plata, latón, zinc etc. y, también, textos con cubiertas, pegados a tapas protectoras a modo de dícticos encuadernados.

Tiseras-tixeras $=$ tijeras para cortar hostias, papel, telas, paños etc.

Tovaias = toallas normales.

Tovallones = toallas grandes. En algunos casos se utiliza este término como sinónimo de cortinas o cortinones y hasta puede hacer referencia y equivaler a la barras o toalleros de madera o de metal donde se colgaban las toallas grandes.

Tramasirgo, tramisirgo = tela entretejida de jergón, lienzo de jerga de color rojizo.

Vazias $=$ vacías, huecas por dentro.

Viada-o = telas, paños, sedas, sábanas, etc. rayadas o listadas al biés, es decir en sentido oblicuo o sesgado.

Viblia $=$ biblia

Vieia-s - vieio-s = vieja-s, viejo-s.

Vestimenta (de preste, de capellán) = vestiduras 0 ropas especiales para quienes presiden o intervienen en los oficios religiosos y, también, el traje oficial o hábito coral de canónigos, beneficiados, capellanes y personas con cargo, revestidos de toga, muceta, birrete, guantes etc.

Xamete = tela especial muy antigua que se utilizaba para brazaletes, cubremangas etc.

Ymagen = imagen, busto, figura, talla... de la Virgen, de los santos. etc. 
TRANSCRIPCION (ACS, CAJ. 44, LEG. $\left.2 N_{-} 26\right)^{8}$

En Era de mill et trezientos et treze annos, en el mes de Dezenbrio, lohan Fferrandez, canonigo, et Nunno Rodriguez, conpanneros de la Yglesia de Salamanca, por si et por ffrey Pedro Braollo,/ ordenadores et desponedores de la manda de lohan Vermudez, tesorero que fue dessa misma Eglesia, dieron por nonbre deste tesorero sobredicho al deán et al cabildo de la devandicha Eglesia de Salamanca / aquestas cosas et aquestos onrramientos de los altares et de la Eglesia de Sancta Maria de la Sey de Salamanca que se siguen: Tres Officieros, dos Responseros sanctorales et dos Responseros dominicales, dos pistoleros, tres / missales, dos evangelisteros, dos capitularios, un colletario, dos proseros, un libro de costumnes, un dominical et un sanctoral de lecciones, una viblia, dos salterios vieios et dos nuevos, una vesti/mienta de preste con dos casulas de panno de peso et una vestimienta de evangelistero et otra de epistolero con sus dalmaticas brancas de seda et una stola de purpura et manipulo de xamete et el manipulo del epistolero de seda viada; / un amito obrado, un velo vermeio pora la cruz, dos vestimientas de capellanes. E la una casula de cendal vermeio et la otra de fustán, et elas estolas et los manipulos vieios; dos camisas et dos amitos, dos capas vieias de purpura, let la una de pavones et la otra de estrellas; quatro çiriales de Limoges vieios, dos grandes e dos pequenos, un fazaruelo pequeno de purpura, dos vinageras, una de cobre y otra de estano, una caldera de agua, una acçerra de ençienso con su cu/char; quatro consiellas <pora hostias >, quatro ceptros et dos palos pora cruzes, una cesta pora tomar elos dyneros de la offerenda, una arca tras la altar, unas tovaias pora alimpiar elas manos, una cruz de christal con pie de laton, et otra/cruz pequena de Limoges con pie de laton; Quatro çiriales de madero que están ante la altar; un frontal de prata, que está sobrel altar mayor con su lave; una cortina que está sobrel altar et es de tovaias; un panno que está tras la altar et / está en él un arvol con otras figuras; Dos tovaias que corren <en> fierros a par del altar; unos tovaiones et otras tovaias de tras el altar; et un ffrontal de peso et otro de purpura con una cruz et con dos pares de façaleias obra-

\footnotetext{
8 Por la dificultad que entraña para la imprenta la puntuación de las ies griegas con punto superpuesto y valor semivocálico (en bastantes casos), dichas letras, puntuadas en el texto de este inventario, las transcribimos aqui sin punto sobrevolado; se omite todo tipo de referencias relativas a las particularidades gráficas, lingüisticas, morfológicas, signos de puntuación, etc., de este romance leonés-castellano, al uso frecuente de la doble $n$, efe y ese, al empleo de formas aferéticas y apocopadas, a las variantes de diptongación y epéntesis, a particularidades vocálicas y léxicas, al valor de algunas partículas aisladas o en posición inicial de palabra (prefijos), etc., etc.
} 
das de seda et/otra de lino obrado con seda, et dos tocas de seda pequenas de listas de oro, en el frontal de prata. Sobrel altar,dos savanas pranas et dos labradas de seda; una arqueta pequena de marfil e una esquileta pequenna, un «te-igitur», una ara,/dos corporales, tres lampadas colgadas antel altar, tres siellas pyntadas poral preste, una mesa pequenna, una cuchar de fierro pora las brasas, unas tiseras pora las ostias, un coyro de oso, un amito obrado. Tras el croçifixo/está un panno labrado con seda et otro panno de lirio con pannos cardenos sobrel croçefixo. Item, seys savanas que andavan con las dalmaticas et con la capa nueva del tesorero. Item, dos dalmaticas nuevas, una de pistolero et otra de/evangelistero; tres huevos de grifo colgados; un panno vermeio viado, una corona del croçefixo et tien seys piedras mayores e otras muchas menudas. Sobre el altar de Sanct Nicholas: un cobertor de xamete/vieio, dos savanas, un frontal de purpura, dos façaleyas lavradas con seda, unas tovaias vieyas et un tovaion, un lampara de aramne, ante el altar; Sobrel altar, dos cruzes, una grande et otra pequenna, una ymagen/ de Sancta Maria, tres caderas vieias poral preste et el diachono et el subdiachono, una esquileta sobrel altar, una capiella de fuste pyntada, una ara con dos corporales. Entre el choro et el altar, un tapede con la estoria/ de Antiochia. Item, en el altar de Sant Lorençio un cobertor de çendal bermeio forrado de panno amariello, dos savanas sirgadas, un frontal de purpura forrado con dos façaleias, un çirial, una ara con dos corporales/, una ymagen de Sancta Maria, una cruz de fuste, unas tovaias et unos tovaiones, una campaneta, una capiella pyntada, una lampada de aramne, las redes con tres puertas et con sus cerraduras et una lave de pecha; dos altares menores et la/puerta dela altar mayor cerrada con dos ferroios que entra uno por otro, et quatro capas de seda et un encesario de prata et dos caliçes de prata con sus patenas et un "ligno domini» con un oral et su casa et con un cendal et con su palo. A la maiestad de Sancta/Maria está una cortina de pano con cielo obrado metido en ella, et tiene una corona de latón dorada con XII piedras <christales>; Et ela maiestad de Sancta Maria tien aderredor quatro alquinnas/ et dos tocas de lino et dos de seda con oro, unas tovaias et una savana; çynco façaleias cosidas en uno con leones et otras dos façaleias et un tovaion et dos pannos que tienen cruzes et un panno de purpura roto, dos pannos vermeios e viados/con vias de oro, una alcotonia nueva viada con vias de oro; un panno de cendal vermeio con oropel que someia maniplo, unas tovaias pora escusar el panno del crucifixo, una tabla con ymagen de Sancta Maria et el angel, un ramo/redondo de pergamino pyntado, dos ymagenes de madero que tienen las candelas et entrellas una arqueta pyntada et dos floreros et un çirial de laton et çynco lampadas de yeso e una de laton. Delantrel cruçifixo dos 
lampadas et / un candelario rodondo sobrel tapede. Primeramientre, quatro escudos del linage Fernan Perez, et uno a corneias, et otro de leon d'oro, et otro a bandas cardenas et d'oro, et otro a bandas d'oro et negras, uno a estrellas et el campo negro et dos so la arca de los organos, uno que fue dorado et otro a bandas de rodas et a veneras. En el altar de Sanct Bernabé, uno a bandas <d'oro> et vermeias, et otro de escaquel. Sobrel coro, uno nuevo a bandas d'oro et vermeias. En/ el pilar, uno nuevo leon d'oro et el campo d'azul. Sobre Alffonsso Yanes, uno a veneras et cabeças de cavallo. En las arcas de la sagristania: un cendal bermeio de sobre la crisma et un velo de çendal vermeio, un panno pequeno de cendal/bermeio fecho pora sobrel altar; veynte frontales de seda entre buenos et malos; veynte et seys amitos con su saco, de los quales el uno es muy noble; Item diez alvas, ela una dellas es muy buena; Item diez dalmaticas de seda vieias pora pis/tolero, et la una dellas es de cendal bermeio, et es muy noble; Item, seys dalmaticas de seda vieias pora evangelistero, et la una dellas es de lino et ela otra de cendal bermeio et es muy noble; Item, diez et siete casulas de seda entre nuevas et vieias et otras dos / casulas de lino; Item, seys pares de buenas tovaias, de las quales, el un par es muy grande et muy luenguo; Item, quatro curtibalidos, muy vieios et muy rotos, para los moços del coro; Item, doze façaleias, dellas de seda et dellas de lino; Item, una senna/morisca; Item, una colcha muy rica que mandó donna Ynés pora frontal; Item, una casula de cendal branco et otra de panno de peso que dio don Fferriando con su estola et con su maniplo, enbuelta en una savana; Item, ocho orales de seda, dellos sanos et del/los rotos; Item, unas façaleias brancas de seda; Item, dos orales de seda listados con listas d'oro et tres tocas de seda pora ante la maiestad; Item, una façaleia branca; Item ocho tocas de seda estrechas e pequenas pora las cruzes, enbueltas en un/panno; ltem, treze amitos buenos et uno roto, enbueltos en un panno; Item, diez e siete maniplos entre buenos et malos; Item, diez e nueve stolas buenas; Item, una fazaleia branca; Item, siete çintas, entre buenas et malas, de lino; Item, treze/corporales; Item, un fazaruello pequeno cubierto de purpura; Item, quatro pannos vieios et rotos de seda pora sobre la altar; Item, dos aras; Item, siete calices de plata con sus patenas, con los dos sobredichos, de los quales son dos dorados de dentro et de fuera con sus pate/nas, et los tres son dorados de dentro et los dos son planos; Item, una vinagera de plata; Item, unos textos cobiertos de plata e dorados en parte, et la una parte tien "sede maiestatis" con quatro evangelistas, et la otra parte tiene crucifixo con quatro ymagenes./ Item, otro encenser de plata; Item, dos cruzes cobiertas de plata; Item, dos «lignos domini» cobiertos de plata et dorados, uno mayor et otro pequeno; Item, dos ciriales da Alimoges con leoncetes et sobredorados; 
Item, otros siete ciriales da Limoges et pedaço / d'otro. Item, dos escodiellas da Limoges sobredoradas; Item, una naveta pora encenso sobredorada con quatro piedras; item, otra vinagera da Limoges; Item, un aguamanil fecho commo leon; Item una maiestad de Sancta Maria en su caseta; Item, una mitra con su/collar et una croça et siete canudos de marfil; Item, un par de luas de seda et una sortija de laton pora los moços; Item, una cruz grande de christal con su casa et con sus lannas de plata; Item, una vara cobierta de plata por al "ligno domini»; Item, un /canudo de laton con piedras en que son las reliquias del pesevre de Ihesu Christo et las vestiduras de Sancta Maria que metieron en la arca de marfil en que son la reliquias, con cadenado de plata et con lave de plata et con lannas de plata et fallez/en la espina de una enpronta (?) de plata, et tiene el deán la lave della et fallez parte de la otra enpronta que está hy quebrada que está de adobar; Item, otras dos arquetas de marfil despegadas et otra sana que tien don Andrés, et en la una daquellas dos iazen dos sortijas de plata/del encensario, una grande et otra pequena, et dos botones de plata pora capas de coro et dos piedras christales; Item, dos ampollas de christal con balsamo; Item, una cinta de lino et una toca de seda con listas de oro; Item, quatro bochetas de fuste vazias; Item, un mosca/dero grande de pennolas de pavon con su ffunda et otras dos de pergamino con sus casas; Item, tres pannos labrados de seda con su funda para las reliquias; Item, quaraenta e çinco capas de seda, entre nuevas et vieias, con seys que ya tienian; Item, treynta e tres acitaras/entre buenas e malas; Item, dos pannos que dizen las naves de antel coro; Item, un panno para cobrir el cruçifixo en el tiempo de la quaraesma; Item, çynquaenta e quatro savanas; Item, un panno lavrado de seda pora sobrel altar; Item, un cendal verde pequeno; Item, seys cortinas; Item, un panno grande tramasirgo; Item, un panno listado de listas d'oro de seda, viado e prieto.//

En la era sobredicha, treze dias por andar de dezebrio, a la terçia, lohan Fernandez, canonigo, et Nunno Rodriguez, companneros de la Eglesia de Salamanca, presentaron et dieron al deán et al cabildo dessa misma Eglesia çynco arcas del tesoro/ del obispo, bien cerradas, las tres cobiertas e las dos rasas, et el deán et el cabildo mandaron las despegar et mandaron las reçibyr con quanto en ellas iazia al arçidiano don Diego et Pedro Yuanes del Ray, et fallaron en la una dellas un/ officiero et un missal et un breviario dominical mistico, et otro sanctoral, et un ordynario que comiença:»Omnipotens Deus", et otro que comiença: "Gallus», et una ara con sus corporales, et otro ordinario que comiença: «Omnipotens Deus", et un prosero; Item, en la otra arca, fallaron/ una tunica de cendal braco et viado, et una dalmatica de seda branca dorada et un panno de peso, et otro panno verde, et otro panno dorado, et otro de xamete pora sobre ca- 
fistol et una dalmatica pintada de leones negres et tres cortibaldos de moços pintados de/pinones, et otra dalmatica pintada de castiellos, et otra dalmatica branca de oro teçida, et otra <dalmatica $>$ teçida de oro et de sirgo, et otra dalmatica branca figurada de caras de omes, et otra dalmatica entreteçida de flores, et otra dalmatica de peso entreteçida de oro, et otra dorada con ruedas doro, et otra entretexida de oro con estrellas, et otra entretexida de oro de panno de peso con su casula desse mismo panno; Item,otra casulla cardena con estrellas doradas; Item, otra casulla blanca de diaspero, et otra casulla blanca entretexida de leones negros; / Item, en la otra arca fallaron un encensario de plata dorado et una naveta de plata con su cuchar de plata et dos vinageras de plata e dos escodiellas de plata, et dos follas de plata redondas pora so los çirios, et dos çiriales de plata, et dos calices de plata sobredorados/ con sus patenas; Item, un aniello de oro grande obispal con camafeo et con piedras buenas; Item, diez aniellos de oro, los quatro con piedras de safiro et los quatro con piedras de rubi, et el uno con piedra de topazio, et el otro con piedra de diamant, et una causeta de marfil, et una / lanna dorada de mitra et boton d'aliofar, et dos esclavones de plata et una cruz de plata dorada con «ligno domini» et con piedras preciosas en su causeta; Item, brago de marfil con una armella de plata dorada; Item, tres libros con taulas cobiertas de plata; Item, un / arca de marfil con reliquias et con dos pendes de marfil; Item, una mitra con veynt e siete piedras preçiosas et con su collar, que tiene veynte hy ocho piedras preçiosas; Item, otra mitra de aliofar dorada con piedras pequennas; Item, otros dos coliares; Item, seys pares de /luvas; Item, tres amitos et dos cintas; Item, una cuchar de plata pora colar agua, et un maniplo et tres estolas; Item, una alva et onze capas et unas calças; Item, un barvero et dos façaleias et un panno. Item, otro dia, conviene a saber, dia de Sancto/Thomé ante de la fiesta de Nathal fezieron abrir las otras dos arquetas del thesoro del obispo et,en la una,fallaron la vestimienta del capellan del obispo con apareiamentos del altar; Item, en la otra, fallaron las letras et los intrumamentos del altar; Item, en la otra fallaron las letras et los instrumentos et los privi/legios de la Eglesia e del obispo; Item, en ese mismo día de Sancto Thomé, en la Era sobredicha, reçibieron el deán et el cabildo de Salamanca de lohan Fernandez, canonigo, et de Nunno Rodriguez, conpannero dessa misma eglesia, por nombre de lohan / Vermudez, thesorero que fue, aquestos libros que se siguen: El primero es "Gregorio Nazianzeno" que comiença: «Proficiscenti mihi» etc.; Item, otro que comiença: "Propicio Christo", etc; Item, otro que comiença; "lacobus» etc.; Item, unos "Sermones de Innocencio" que comiençan: "Innocentius episcopus"; Item, "Gregorius super Ezechielem» que comiença: "In nomine Sancte Trinitatis"; Item, "Expositio Origenis", 
que comiença: "Colende me parvo subienctum»; Item, un libro de Gregorio que comiença: "Ex plene verbis"; Item, unos "Sermones" que comiençan: «Dicite pusillanimes"; Item, ela exposition del "Salterio" que comiença: «Prophetas Spiritus Sancti»; Item, "Epistolas de Sant Paulo", que comiença: "Paulus servus"; Item, "Quadernos de los cinco libros de Moysen", que comiença: "Volo frates"; Item, otro "Quaderno" que comiença: "Deus est incarnatus"; Item, "Sermones" que comiença: "Quid gloriaris"; Item, "Sermones", que comiença: "Cum apropinquasset»; Item, "Expositio del Salterio», que comiença: «Ffelices sunt auditores»; Item, un "Exodo" de glosa menor, que comiença/: "Hec sunt nomina"; Item otro "Exodo" de glosa menor, que comiença "Hec sunt nomina»; Item, "Psalterio" glosado de glosa menor, que comiença: "Beatus vir»; Item, «Epistolas de Sanct Paulo» glosadas, que comiençan: "Principia rerum»; Item, un "Libro de sentencias»/ que compieça: "Multi»; Item, un «Libro de los Prophetas" que comiença: "Nemo"; Item, un "Evangelio de Sanct lohan", que comiença: "Hic est lohannes»; Item, un grant "Psalterio" glosado que comiença: "Cum omnes prothetas"; Item, "Sermones", que comiença: "Omnem/ pecatum»; Item, un libro que comiença: "Apocalipsis"; Item, un "Libro de Sanct Ysidro" de letra gallega; Item, "Questiones de teologia", que compiença: "De fide»; Item, "Lucidario", que compiença: «Rogatus»; Item, otro libro que compieça "Magni opere»; Item otro "Libro de Sanct Iheronimo" que compieça:"Lavabo" etc.; Item otro libro de Sant Ysidro, que compieça "Quorumdam Sanctorum Patrum»; Item, un "Salustio", que compieça: "Salustii Chrispi»; Item, un "Virgilius", que compieça "Bucolicis"; Item, un / "Lucidario", que comiença: "Rogatus"; Item un "Boeçio" que comiença: "Carmine qui quondam"; Item, otro libro que comiença: «Pastoralis cure»; Item, otro libro que compieça: «Lex sacrilegorum».//

Summa ystorum librorum precedentium: treynta e syete. 